\title{
Startup Founders' Personality Attributes in Crowdfunding Campaigns: The Relevance of Hubris and Charisma in Raising Seed Funding Online
}

\author{
Janina Sundermeier \\ Freie Universität Berlin \\ janina.sundermeier@fu-berlin.de
}

\author{
Tyge Kummer \\ Griffith University \\ t.kummer@griffith.edu.au
}

\begin{abstract}
Startup founders often display personality traits associated with charisma and hubris. Existing literature contains rich evidence on the relevance of these traits for traditional investments settings that involve a personal interaction between the entrepreneur and the investor. However, the state of theory development on how hubris and charisma also influence the outcomes of raising seed funding online from non-professional investors can still be considered as nascent as a result of missing empirical evidence. We draw upon dual-process theory and argue that hubris and charisma are of particular relevance as they trigger intuitive decision-making processes of non-traditional investors. Our empirical setting involves a true experiment based on three versions of a crowdfunding pitch video that was recorded in collaboration with a professional actor. The primary outcomes suggest that both hubristic and charismatic entrepreneurs are more successful in sourcing capital from the crowd as they are perceived as more trustworthy and passionate.
\end{abstract}

\section{Introduction}

"We are not won by arguments that we can analyze, but by tone and temper, by the manner which is the person himself" [5].

Crowdfunding provides startup founders with a novel opportunity to raise seed funding from nonprofessional investors through online marketplaces $[1,2]$, such as Kickstarter and IndieGoGo. Examinations of the determinants that influence the investment decisions of crowd funders are increasingly gaining popularity in the information systems (IS) literature but the overall state of theory development is still at an 'embryonic state' [3, 4]. We contribute to this stream of literature by examining the importance of startup founders' personality traits on the success of online crowdfunding campaigns.

The previous quote illustrates the duality of information processing that is not necessarily based on analytical arguments but rather on feelings associated with the "tone and temper" of an individual [5, 6]. Empirical evidence suggests that certain personality traits trigger intuitive decision making that cannot be explained with rational arguments [7, 8]. We argue that the influence of personality traits on intuitive information processing becomes particularly evident in crowdfunding scenarios as the information provided is limited and does not allow unskilled non-professional investors to derive purely rational decisions.

One of these traits is charisma [9, 10]. In fact, charismatic entrepreneurial leaders are frequently described as being able to articulate their ideas and visions in a charming, attractive, and persuasive manner [11]. Certain characteristics of their verbal and non-verbal communication leads to high performance levels, commitment, and satisfaction among their peers, who often seem to follow them intuitively $[12,13]$. Similar effects are also observed in cases of hubristic entrepreneurial leaders, such as Steve Jobs, Mark Zuckerberg, and Jeff Bezos. These founders are often characterized by various extreme traits, such as excessive pride, exaggerated selfconfidence, inflated positive self-evaluations and arrogance [7, 14-16].

Additional knowledge on how hubristic and charismatic startup founders are perceived by third parties is of considerable importance as hubris and charisma are two phenomena that frequently occur within the startup context [7, 14]. The "tone and temper" of these founder personalities is perceived is especially relevant in order to raise funding. Entrepreneurs have to convincingly present themselves and their business ideas in front of potential investors in order to obtain financing. In this context, crowdfunding campaigns are particular relevant as they allow entrepreneurs to raise money 
from a large pool of non-professional investors [5, 17].

We apply multi-model methods in order to examine the influence of entrepreneur's personality traits on the judgement and decision making of nonprofessional investors in crowdfunding campaigns. We further explore how entrepreneur's personality traits can be linked to hubris and charisma. In order to address these research questions, the paper relies on dual-process theory of information processing in order to analyze the intuitive judgment and decision making of non-professional investors in crowdfunding settings.

To that end, we decided to conduct a true experiment based on a manipulated crowdfunding pitch video. The video allows us to gather data that reflects the complexity of hubris and charisma including speech, gestures, explanatory models, and inflections [18, 19]. Multimodal methods are well suited to capture those verbal and non-verbal elements alike and to conduct more fine-grained analyses based on this data [20]. In the following, we outline the theoretical background and explain the method.

\section{Theoretical background \& hypotheses}

\subsection{Intuitive information processing}

We refer to the dual-process theory of information processing in order to determine how hubristic and charismatic startup founders are perceived by non-professional investors [21, 22]. This theory proposes two separate modes for cognitive information processing. One is analytical, deliberate, controlled and relatively slow. This mode is used when individuals solve consciously a complex problem $[22,23]$. The second mode is affective. It can be characterized as intuitive, automatic, fast, and driven by feelings [24]. This mode also involves the cognitive processes that influence the perception of risks, which is particularly relevant in relation to financial investments [25]. Prior research indicates that emotional processes within the cognitive system impede rational risk judgment. Therefore, risk estimations are often not based on analytical processes that systematically assess the probabilities of certain risks [21]. This reasoning already shows that intuition and analysis are defined as the opposite ends of a continuum that displays modes of information processing [26]. Every decision addresses a particular cognitive mode on this continuum that contains a combination of intuitive and analytical processing. We follow this understanding of dual processing in order to examine an investment decision in a crowdfunding scenario. While the analysis mode is the same across groups, we manipulate the intuitive component of a crowdfunding pitch through multimodal methods.

The affect heuristic provides a theoretical explanation for the underlying effects in the intuitive information processing mode. In an individual's mind, objects and events are tagged to varying degrees with affect. This includes emotions and feelings based on previous experiences. In the process of judgement and decision-making, an individual consults the "affect pool" that contains all positive and negative tags consciously or unconsciously associated with the representations $[23,24]$. To that end, the affect serves as a decision cue. The initial affective impression cannot be controlled by the individual as the tags create a mental short-cut that cannot be disabled. This thinking mode is extremely efficient, as it requires almost no mental effort leading to the term "affect heuristic" [22]. Individuals often utilize the affect heuristic instead of cognitive efforts, as it is difficult for the human mind to consider all available information. Instead, only limited 'computing capacities' of the brain are used in order to process information and derive decisions on a bounded rational basis [6].

This implies that instead of making a rational judgement based on all available data, feelings are in some situations the actual driver of judgement and decision making $[23,24]$.

\subsection{Determinants of crowd funders' investment decisions}

The state of theory development on how intuitive and analytical judgement is manifested in the decision-making of non-professional investors can still be considered as nascent due to missing empirical evidence [27]. Crowd funders often lack a professional investment background compared to standard financial intermediaries [4]. They pledge smaller amounts of money based on the value proposition presented by startup founders through video pitches or other means [1, 3, 28]. Such crowdfunding campaigns enable founders to source seed funding from a large crowd that invests money in return for future products, equity, or loans [2, 29].

Existing empirical evidence identified several determinants of crowd funders' investment decisions. It is found, for instance, that displaying social capital, such as access to large social networks, positively influences the trustworthiness and credibility of crowd funders [30, 31]. In addition, perceived 
cultural differences are determined to influence the transaction likelihoods: greater perceived differences are associated with lower transaction likelihoods [1].

We contribute to this state of scientific knowledge by examining the importance of startup founders' personality traits on the success of online crowdfunding campaigns.

\subsection{Startup founders' personality traits}

Hubris and charisma combine several personality traits that are frequently attributed to entrepreneurial leaders and affect how entrepreneurs are perceived by stakeholders, such as (non-professional) investors [7, 8]. Both traits emerged from different research disciplines that contribute meaningfully to the above outlined research questions.

Hubris is a cognitive bias that is characterized by excessive pride, exaggerated self-confidence, inflated positive self-evaluations and arrogance [7, 14, 16]. The concept originates from Greek mythology and is applied in management and entrepreneurship literature in order to describe the beliefs and behaviors of entrepreneurial leaders that hold a position of power [32-34]. Famous founder personalities, such as Steve Jobs, Mark Zuckerberg, and Jeff Bezos, are frequently attributed with hubris. The bias is described to affect their verbal and nonverbal articulation of ideas and visions [14, 15, 35].

Charisma is defined as a value-based leadership style that utilizes symbols, emotions, and a shared vision in order to inspire followers [36]. Research on charisma has a long tradition in management literature and positive attributions of charismatic CEOs, that are described as charming, attractive, and persuasive by their peers [11], are already well researched and documented [10, 11]. Famous personalities are, for instance, Barack Obama and Martin Luther King, who both are described to articulate their missions in a charismatic manner. Surprisingly, empirical evidence on how charismatic startup founders are perceived by third parties, especially (non-professional) investors, is still missing [37].

\subsection{Hypotheses}

Drawing upon the previously presented insights on dual process theory and entrepreneurial personality traits, we argue that the intuitive component of judgement and decision-making is of particular importance for investment decisions by crowd funders. Specifically, we argue that especially non-verbal expressions, such as tone of voice and facial expressions, have an important influence on how crowd funders perceive startup founders and their ideas [17, 36]. These contextual elements of a crowd funding pitch are suggested to create an emotional stage that leads crowd funders, with only minor experiences in investing money, to rely on intuition rather than the logical arguments presented $[6,24]$.

Therefore, we assume that intuition is among others an important determinant of crowd funding success and state:

H1: The success of a crowdfunding campaign is influenced by intuitive information processing.

Furthermore, research in relation to entrepreneurial personality and marketing suggests that personality traits influence the perception of others. Traits such as charm, attractiveness, persuasive communication, articulation of compelling visions, and arousing and inspiring commitment are associated with charisma and regarded as positive in relation to the charismatic leadership style [11]. In contrast, hubris is associated with personality traits that are often associated with negative aspects such as negative interpersonal consequences [38] and difficulties to identify themselves with the leader [39]. However, little is known about the personality traits in relation to hubris and the proposed negative implications do not necessary hold true as many successful leaders show hubris. A possible explanation provides the marketing literature. This line of research suggests that traits such as empathy, customer service orientation, extroversion, ego-drive, and optimism characterize a successful sales person [40]. We argue that a video product pitch in a crowdfunding campaign is comparable to a traditional sales event with the exception that the entrepreneur tries to sell a potential product that does not exist at that stage. Not every sales person trait can be assigned to charisma or hubris (e.g., extroversion). However, we argue that empathy and customer service orientation reflect charismatic traits, while ego-drive and optimism represent hubris. We state:

$\mathrm{H} 2$ : Entrepreneur's personality traits influence judgement and decision-making of (non-professional) investors in crowdfunding campaigns.

In line with the affect heuristic, we argue that the individual affect pool contains personal preferences and experiences. Consequently, the affect can differ between individuals as the established mental shortcuts are triggered by different feelings. This 
explains why some individuals can be convinced with personality traits such as ego-drive (which might cause feelings in relation to competence and passion) while others feel understood through the personality trait of empathy and related shared values. Formally, we state:

H3: Entrepreneur's personality traits in relation to hubris and charisma trigger different affects that contribute individually to the success of a crowdfunding campaign.

\section{Methodology}

An experimental design was chosen with one between-group factor entrepreneur style with three levels (hubris, charisma, and neutral) and one trial in order to explore judgement and decision-making of non-professional investors. The investment decision was based on a real-world crowdfunding campaign that was selected based on the following criteria: (1) a single founder initiated the project, (2), the founder succeeded in raising the targeted amount of money, (3) product and pitch are easy to understand, (4) product price is relatively low, and (5) the product is still relatively unknown.

In order to identify the pitch, we considered the most successful crowdfunding pitches across platforms and eventually selected a non-absorbent Tshirt. Next, we determined charismatic and hubris characteristics that can be displayed in a video pitch. This resulted in a list of attributes for the representation of hubris, charisma, and a neutral pitch. The neural pitch without treatment is used for the control group. Table 1 outlines some of the selected differences between the videos. In total, we identified 14 characteristic attributes in 10 categories based on an extensive literature analysis that also involved publications on how entrepreneurs act when presenting their business ideas on stage or in written documents, such as business plans and pitch decks $[14,36]$.

Each video has a runtime of about three minutes. All three pitches were recorded with a professional actor using video recording facilities within a university. The list of attributes was utilized in order to develop scripts for the three product pitches. While the general arguments - such as cost savings in relation to washing - were the same in all three versions, the presentation style and the emphasis on particular aspects differed between the pitches. Video recording and editing were completed in December 2017.
We currently conduct the experiment in a controlled classroom environment. Participants have basic knowledge about business administration including entrepreneurship and are randomly assigned to one out of three groups (neutral, charisma, or hubris). To that end, we are conducting a true experiment. The experiment begins with the distribution of a questionnaire and the related collection of descriptive information such as age, gender and educational background. Then, in dependence of the group allocation, either the neutral, the charisma, or the hubris pitch is shown. This is followed by a question regarding the intended purchase behavior as well as the perceived trustworthiness and passion of the entrepreneur in the questionnaire. Participants can select between no investment, one T-shirt for 35 Euro, two T-shirts for 65 Euro, and seven T-Shirts in different colors for 200 Euro. On this basis, we are able to identify differences in the purchase behavior between all three versions of the video pitch. Furthermore, variables will be collected in order to determine how the participants perceived the manipulated personality traits of the entrepreneur. This includes their perception of empathy, customer orientation, egodrive, optimism, and extroversion. Additionally, we will collect data regarding the perceived charisma, hubris, voice, and gestures in order to determine whether the treatment was successful. We will further collect data on the participant's crowdfunding experience, the personal budget and a finance knowledge test in order to include these aspects as control variables. The data analysis is based on an ANCOVA with the fixed factor entrepreneur style, the dependent variable intended purchase behavior as well as the control variables crowdfunding experience, personal budget, and finance knowledge. Effects of the remaining variables will be examined as part of the post hoc analysis. 
Table 1. Selected differences between the three versions of the video pitch.

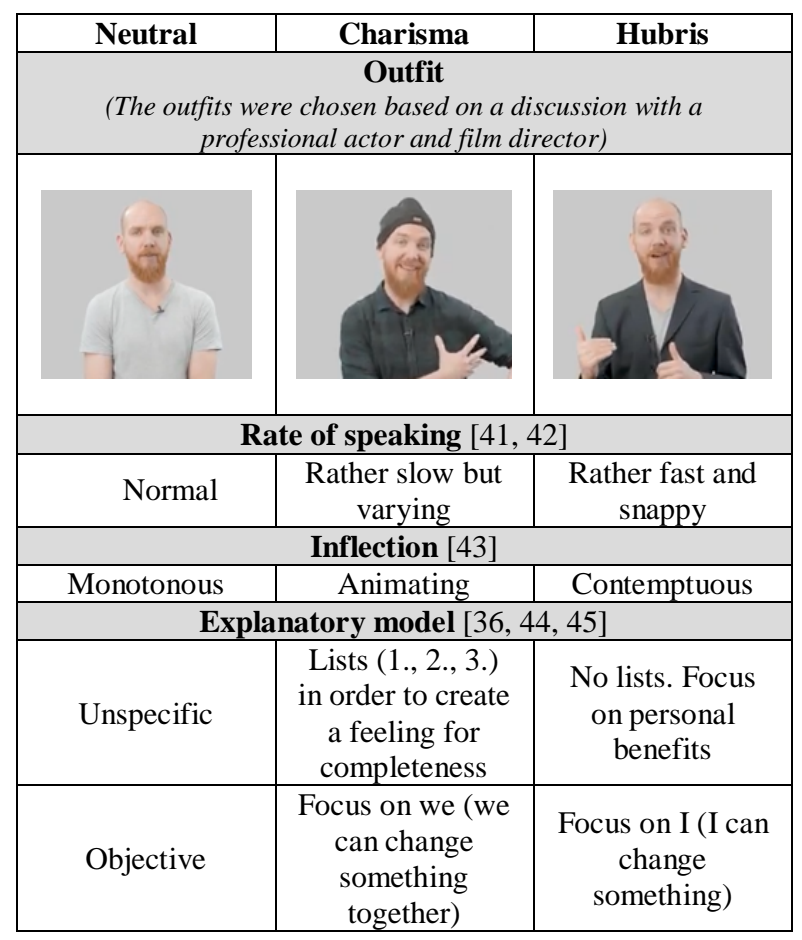

\section{Primary findings \& outlook}

A pre-test of the experiment was conducted with 60 business students in April 2018. The learnings from this pre-test were used to refine the questionnaire and setting of the experiment.

The actual experiment is currently conducted with 210 business students that are randomly assigned to one of the three groups (neutral, hubris and charisma). The primary findings indicate that that both charismatic and hubristic startup founders are more successful in sourcing capital from the crowd compared to entrepreneurs without noticeable personality traits. Specifically, the data indicates that hubris influences how the founders are perceived with regard to their trustworthiness, whereas charismatic entrepreneurs are perceived as passionate. These associations are derived intuitively and positively influence the investment decisions of the crowd funders. To that end, we believe that our results will provide valuable insight into the success factors of crowdfunding.

The data collection will be completed by 24.06.2018 and the analysis is again conducted thoroughly. We are looking forward to presenting the detailed findings at the $52^{\text {nd }}$ HICSS. In addition, a second study is planned in order to determine whether our study is subject to selection bias. We have carefully selected a sample of students with highly diverse backgrounds who have all deliberately chosen to enroll in an elective entrepreneurship class. We argue that this choice is an indicator for their entrepreneurial mindset, which could be a characteristic of crowd funders who are interested in investing smaller amounts of money in innovative projects. However, we are aware that a potential selection bias could occur and a second study with a more diverse sample is planned to address this concern. Our findings have practical implications as they could help crowd funders to raise money. Additionally, the findings could stimulate further research on personal characteristics that influence the success of entrepreneurs.

\section{References}

[1] G. Burtch, A. Ghose, and S. Wattal, "An Empirical Examination of the Antecedents and Consequences of Contribution Patterns in Crowd-Funded Markets," Information Systems Research, vol. 24, no. 3, pp. 499-519, 2013.

[2] A. Schwienbacher and B. Larralde, "Crowdfunding of Small Entrepreneurial Ventures," in Oxford Handbook of Entrepreneurial Finance, Cumming D., Ed., New York: Oxford University Press, 2012, pp. 369-390.

[3] V. Kuppuswamy and B. L. Bayus, "Crowdfunding Creative Ideas: The Dynamics of Project Backers," in The Economics of Crowdfunding, D. Cumming and K. Hornuf, Eds., Heidelberg: Springer, 2018, pp. 151-182.

[4] E. Mollick, "The Dynamics of Crowdfunding: An Exploratory Study," Journal of Business Venturing, vol. 29, no. 1, pp. 1-16, 2014.

[5] R. A. Baron and G. D. Markman, "Beyond social capital: How social skills can enhance entrepreneurs' success," The academy of management executive, vol. 14, no. 1, pp. 106-116, 2000.

[6] D. Kahneman and A. Tversky, "Conflict resolution: a cognitive perspective," in Barriers to Conflict Resolution, K.J. Arrow and Stanford Center on Conflict and Negotiation, Eds., Stanfort: W.W. Norton, 1995, 3rd Chapter.

[7] T. A. Judge, R. F. Piccolo, and T. Kosalka, "The bright and dark sides of leader traits: A review and theoretical extension of the leader trait paradigm," The Leadership Quarterly, vol. 20, no. 6, pp. 855875, 2009.

[8] C. J. Resick, D. S. Whitman, S. M. Weingarden, and N. J. Hiller, "The bright-side and the dark-side of CEO personality: Examining core self-evaluations, 
narcissism, transformational leadership, and strategic influence," Journal of Applied Psychology, vol. 94, no. 6, p. 1365, 2009.

[9] J. A. Conger, "Charismatic and transformational leadership in organizations: An insider's perspective on these developing streams of research," The Leadership Quarterly, vol. 10, no. 2, pp. 145-179, 1999.

[10] G. Yukl, “An evaluation of conceptual weaknesses in transformational and charismatic leadership theories," The Leadership Quarterly, vol. 10, no. 2, pp. 285-305, 1999.

[11] M. Weber, The theory of social and economic organization, trans. New York: AM Henderson and Talcott Parsons, 1947.

[12] J. B. Fuller, C. E. P. Patterson, K. Hester, and D. Y. Stringer, "A quantitative review of research on charismatic leadership," Psychological reports, vol. 78, no. 1, pp. 271-287, 1996.

[13] B. Shamir, R. J. House, and M. B. Arthur, "The motivational effects of charismatic leadership: A self-concept based theory," Organization science, vol. 4, no. 4, pp. 577-594, 1993.

[14] H. Bollaert and V. Petit, "Beyond the dark side of executive psychology: current research and new directions," European Management Journal, vol. 28, no. 5, pp. 362-376, 2010.

[15] P. M. Picone, G. B. Dagnino, and A. Minà, "The origin of failure: a multidisciplinary appraisal of the hubris hypothesis and proposed research agenda," The Academy of Management Perspectives, vol. 28, no. 4, pp. 447-468, 2014.

[16] J. Sundermeier, "Start-Up (s) with Hubris-The Effects of Hubris on the Performance of Core Entrepreneurial Functions," Dissertation, Freie Universität Berlin, Berlin, 2017.

[17] L. Balachandra, A. R. Briggs, K. Eddleston, and C. Brush, "Pitch like a man: Gender stereotypes and entrepreneur pitch success," Frontiers of Entrepreneurship Research, vol. 33, no. 8, p. 2, 2013.

[18] V. Petit and H. Bollaert, "Flying too close to the sun? Hubris among CEOs and how to prevent it," Journal of Business Ethics, vol. 108, no. 3, pp. 265-283, 2012.

[19] J. Streeck, C. Goodwin, and C. LeBaron, Embodied interaction: Language and body in the material world: Cambridge University Press, 2011.
[20] P. Gylfe, H. Franck, C. LeBaron, and S. Mantere, "Video methods in strategy research: Focusing on embodied cognition," Strategic Management Journal, vol. 37, no. 1, pp. 133-148, 2016.

[21] S. A. Sloman, "The empirical case for two systems of reasoning," Psychological Bulletin, vol. 119, no. 1, p. 3, 1996.

[22] P. Slovic, E. Peters, M. L. Finucane, and D. G. MacGregor, "Affect, Risk, and Decision making," Health Psychology, vol. 24, no. 4S, 35-53, 2005.

[23] J. Evans, "In Two Minds: Dual-Process Accounts of Reasoning," Trends in Cognitive Sciences, vol. 7, no. 10, pp. 454-459, 2003.

[24] P. Slovic, M. Finucane, E. Peters, and D. G. MacGregor, "The Affect Heuristic," in Heuristics and Biases: The Psychology of Intuitive Judgment, T. Gilovich, D. Griffin, \& K. D, Ed., New York: Cambridge University Press, 2002, 84-106.

[25] D. Hammond, "Health Warning Messages on Tobacco Products: A Review," Tobacco Control, vol. 20, no. 5, pp. 327-337, 2011.

[26] K. R. Hammond, Human Judgment and Social Policy: Irreducible Uncertainty, Inevitable Error, Unavoidable Injustice. Oxford: Oxford University Press on Demand, 2000.

[27] A. C. Edmondson and S. E. McManus, "Methodological fit in management field research," Academy of Management Review, vol. 32, no. 4, pp. 1246-1264, 2007.

[28] A. Agrawal, C. Catalini, and A. Goldfarb, "Some Simple Economics of Crowdfunding," Innovation Policy and the Economy, vol. 14, no. 1, pp. 63-97, 2014.

[29] P. Belleflamme, T. Lambert, and A. Schwienbacher, "Crowdfunding: Tapping the Right Crowd," Journal of Business Venturing, vol. 29, no. 5, pp. 585-609, 2014.

[30] M. Lin, N. R. Prabhala, and S. Viswanathan, "Judging Borrowers by the Company They Keep: Social Networks and Adverse Selection in Online Peer-to-Peer Lending," Management Science, vol. 59, no. 1, pp. 17-35, 2009.

[31] J. Zhang and P. Liu, "Rational Herding in Microloan Markets," Management Science, vol. 58, no. 5, pp. 892-912, 2012.

[32] M. Hayward and D. C. Hambrick, "Explaining the premiums paid for large acquisitions: evidence of CEO hubris," Administrative science quarterly, pp. 103-127, 1997. 
[33] D. Trumbull, "Hubris: a primal danger," Psychiatry: Interpersonal and Biological Processes, vol. 73, no. 4, pp. 341-351, 2010.

[34] P. Woodruff, "The shape of freedom: democratic leadership in the ancient world," in The quest for moral leaders: Essays on leadership ethics, J. B. Ciulla, T. L. Price, and S. E. Murphy, Eds.: Edward Elgar Publishing, 2005, pp. 13-27.

[35] M. Hayward, Ego check: why executive hubris is wrecking companies and careers and how to avoid the trap. Chicago: Kaplan, 2007.

[36] J. Antonakis, M. Fenley, and S. Liechti, "Can charisma be taught? Tests of two interventions," Academy of Management Learning \& Education, vol. 10, no. 3, pp. 374-396, 2011.

[37] D. Miller, "A downside to the entrepreneurial personality?," Entrepreneurship Theory and Practice, vol. 39, no. 1, pp. 1-8, 2015.

[38] C. van Damme, V. Hoorens, and C. Sedikides, "Why Self-Enhancement Provokes Dislike: The Hubris Hypothesis and the Aversiveness of Explicit SelfSuperiority Claims," Self and Identity, vol. 15, no. 2, pp. 173-190, 2015.

[39] K. T. Haynes, M. A. Hitt, and J. T. Campbell, "The Dark Side of Leadership: Towards a Mid-Range Theory of Hubris and Greed in Entrepreneurial Contexts," Journal of Management Studies, vol. 52, no. 4, pp. 479-505, 2015.

[40] J. M. Loveland, J. W. Lounsbury, S.-H. Park, and D. W. Jackson, "Are salespeople born or made? Biology, personality, and the career satisfaction of salespeople," Journal of Business \& Industrial Marketing, vol. 30, no. 2, pp. 233-240, 2015.

[41] A. Rosenberg and J. Hirschberg, "Charisma Perception from Text and Speech," Speech Communication, vol. 51, no. 7, pp. 640-655, 2009.

[42] R. F. Baumeister, J. D. Campbell, J. I. Krueger, and K. D. Vohs, "Does High Self-Esteem Cause Better Performance, Interpersonal Success, Happiness, or Healthier Lifestyles?," Psychological Science in the Public Interest, vol. 4, no. 1, pp. 1-44, 2003.

[43] H. S. Friedman, R. E. Riggio, and D. F. Casella, "Nonverbal Skill, Personal Charisma, and Initial Attraction," Personality and Social Psychology Bulletin, vol. 14, no. 1, pp. 203-211, 1988.

[44] Z. W. Todorovic and F. K. Schlosser, "An Entrepreneur and a Leader!: A Framework Conceptualizing the Influence of Leadership Style on a Firm's Entrepreneurial Orientation-Performance
Relationship," Journal of Small Business \& Entrepreneurship, vol. 20, no. 3, pp. 289-307, 2007.

[45] B. M. Bass, Bass and Stogdill's Handbook of Leadership, 3rd ed. New York: Free Press, 1990. 